ПАРМА Роман Васильевич - кандидат политических наук, доцент департамента политологии факультета социальных наук и массовых коммуникаций Финансового университета при Правительстве РФ (125993, Россия, г. Москва, ГСП-3, Ленинградский пр-кт, 49; rvрагта@ mail.ru)

\title{
ТЕОРЕТИЧЕСКИЕ МОДЕЛИ ОТНОШЕНИЙ МЕЖДУ ПОКОЛЕНИЯМИ ГРАЖДАН
}

Аннотация. В условиях общественных трансформаций межпоколенческие отношения вызывают интерес исследователей в качестве одного из важных факторов изменений. Теоретические основания современных исследований заложены рядом ключевых моделей поколений, в числе которых смена поколений, трансмиссия, циклы, разрывы, стратегии и цифровизация. Каждая из обозначенных моделей поколений учитывает различные факторы и механизмы формирования отношений, задавая особый ракурс исследований.

Ключевые слова: теория поколений, модели отношений поколений, смена поколений, возрастная дифференциация, трансмиссия поколений, циклы поколений, разрывы поколений, стратегии поколений, цифровизация поколений

\footnotetext{
Статья подготовлена по результатам исследований, выполненныхзасчет бюджетныхсредств по государственному заданию Финансовому университету.
}

B период общественных трансформаций отношения между поколениями приобретают особую важность. Традиционно в исследованиях возмутителем спокойствия и зачинщиком конфликта видится молодежь, которая идет в авангарде переустройства существующих порядков, бросая вызов старшим. Сформированные политические ценности и жизненные установки молодого поколения потенциально содержат возможности для активации радикальных действий [Пырма 2017]. В молодежной среде находят распространение деструктивные настроения, возникает опасность протестных и экстремистских выступлений [Шатилов 2019]. Отчасти поведение молодежи в современном обществе объясняется значительной дифференциацией по уровню критического мышления, способности определять достоверность и значимость медийного контента, который стал ключевым источником информации. Цифровые коммуникации для молодого поколения стали средством профессиональной, социокультурной и гражданской адаптации [Бродовская и др. 2019]. Между тем теории поколений позволяют открывать более широкую и сложную картину формирования и взаимоотношений социальных возрастных групп. Здесь рассмотрим наиболее часто используемые в исследованиях концептуальные модели межпоколенческих отношений.

Смена поколений. Основоположником теории поколений стал немецкий социолог К. Мангейм, который создал модель исторической смены возрастных групп. Для определения социальных общностей было использовано понятие «поколение», которое в современной социологии приобрело значение «когорта». Рожденные в один исторический период и в одной социокультурной среде люди в течение ключевого периода формирования личности переживают в общем контексте одни события. Представители когорты имеют определенное сходство, поскольку наделены общими характеристиками в историческом процессе [Мангейм 2000]. Период, в который рождается когорта, ограничивает ее представителей определенным опытом и диапазоном возможностей, 
формируя «коллективные воспоминания». Историческая память поколений служит основой для формирования установок, мыслей и поведения граждан [Joshi, Dencker, Franz 2011]. При этом формирование поколения происходит в процессе осмысления индивидом своей жизни в контексте истории и интерпретации поведения других. Принадлежность к когорте, подобно положению в социально-экономической структуре общества, ограничивает представителей поколения узким кругом возможных переживаний, предрасполагая к особенностям мышления [Foster 2013].

Ментальные различия когорт приводят к конфликту поколений. Молодая когорта, внутри которой возникают дивергентные группы, пытается изменить существующее положение и взгляды в обществе. Старшие когорты держатся за сохранение существующего социального порядка, сохраняя традиционные ценности. При этом внутри когорт также существуют различия, образуются «поколенческие единицы», которые имеют выраженные отличия и могут выступать антагонистами. Вместе с тем вхождение в состав когорты оказывает сильное влияние на ценности и поведение представителей, подобно классовым отношениям в обществе.

Положение К. Мангейма о непрерывной смене когорт и ее влиянии на общественное развитие получило современное раскрытие в концепции возрастной стратификации. Понимание отношений между поколениями следует рассматривать в ракурсе распределения по возрастным группам. Согласно данной концепции, общество делится на иерархию социально признанных возрастных слоев. Каждый слой состоит из сходных по возрасту членов, чье поведение регулируется схожим набором норм поведения. Представители возрастных слоев различаются по своим возможностям получать и контролировать социальные ресурсы. Молодежь обладает меньшими ресурсами по сравнению со старшими. Социологи видят в таких различиях интересов между когортами основание для возможных конфликтов в обществе. С течением времени проблема поколений начинает отражать напряженность противоречий между устоями и изменениями, традициями и инновациями в социальном порядке современного общества [Bengtson 1989].

Возрастная стратификация отношений между поколениями применима к политической сфере. Когда систему возрастной стратификации рассматривают как аналогичную, например, классовой или гендерной системе, из этого следует, что групповая солидарность может развиваться внутри каждой возрастной когорты. Как открытый, так и скрытый конфликт интересов может возникать между различными когортами. Концепция социальных поколений рассматривает конфликты, когда мятежная молодежь бросает вызов авторитету старших поколений в качестве движущей силы истории ${ }^{1}$. Темы солидарности и конфликта находят отражение в современных социологических исследованиях взаимоотношений поколений.

Трансмиссия поколений. Помимо К. Мангейма, наиболее значительный вклад в разработку теории поколений внесла американский антрополог М. Мид, которая разграничила постфигуративный, кофигуративный и префигуративный типы культуры. В постфигуративной культуре, присущей примитивным обществам, изменение протекают крайне медленно, дети учатся у своих предшественников, прошлое взрослых становится будущим новых поколений, прожитое старшими укладывается в схему будущего детей, передается чувство неизменной преемственности, воспроизводится образ жизни. В кофигуратив-

${ }^{1}$ Esle A. 2015. Generations in History (ed. by J.D. Wright). - International Encyclopedia of the Social \& Behavioral Sciences. $2^{\text {nd }}$ ed. Elsevier. P. 857-860. 
ной культуре, соответствующей уже цивилизациям, дети и взрослые учатся у сверстников, происходят медленные и неровные изменения, наблюдаются большие различия в знаниях людей, принадлежащих к разным социальным группам, классам, странам, взрослые обладают большими званиями и опытом, чем молодые люди. В префигуративной культуре, что соответствует современному обществу, взрослые уже учатся у своих детей, когда дети вырастают в новом для старших мире, молодежь, схватывая неизвестное будущее, наделяется новыми правами.

Опираясь на исторический опыт общественного развития стран Запада, М. Мид современную цивилизацию характеризует так же, как проспектовую, обращенную в будущее, в которой старшие в меньшей мере передают свой опыт младшему поколению, а скорее учатся у них. Взрослые заражаются «энергетикой действия», выстраивая наряду с «серьезным миром» работы и семьи, ответственности и обязанностей параллельный «игровой мир». М. Мид учитывает зависимость отношений между поколениями от социальных и технологических изменений, отмечая трансмиссию культуры, передачу информации и опыта как от родителей к детям, так и от детей к родителям [Мид 1988]. Изменение культурных элементов происходит в стохастическом ритме, поэтому различия между каждым поколением имеет ряд характерных особенностей.

Циклы поколений. Оригинальная теория поколений Штрауса-Хоу построена на циклических изменениях. Согласно исследованиям У. Штрауса и Н. Хоу, во многих странах периодически возникают глубокие кризисы, которые действуют как «сезонный цикл». Исторические циклы поколений совпадают с великими событиями. Теория поколений Штрауса-Хоу предполагает существование четырех разных поколений, каждое из которых соответствует определенному «сезонному архетипу». Первое поколение каждого цикла подобно весне: это поколение, рожденное после великого кризиса. «Весенний сезон» дает начало упорядоченным обществам с сильными институтами и глубоким чувством коллективного прогресса, с навязываемой культурой большинства, которые формируют «молчаливое поколение». Для последующего «летнего сезона» характерно противоположное поведение, когда происходят бурные проявления индивидуализма, сопровождаемые значительными трудностями адаптации к установленным нормам. Страстное и творческое поколение инициирует великие преобразования в культуре и установленных ценностях. «Осенний сезон» приносит безответственный индивидуализм, в котором исчезает чувство общности, преобладают цинизм и падение нравственности, растет социальное неравенство и стремление к безусловной свободе личности. На «зимний сезон» приходятся глубокий политический и социальный кризис, войны и конфликты, которые подвигают к возрождению гражданских чувств и общественных ценностей. В свою очередь, социализация в детском возрасте порождает идеалистический, реактивный, гражданский и адаптивный архетипы поколений, последовательно повторяющиеся в ритме с циклом кризисов и пробуждений [Howe, Strauss 1991].

Цикличность обусловливает смену поколений в определенные исторические периоды и повороты общественного развития. По мере вступления каждого поколения в последующие фазы жизни и новые социальные роли существенно изменяются ценностные установки и паттерны поведения, которые приводят к новым поворотам общественного развития. При этом исторические события и смена поколений оказываются взаимообусловленными. Происходящие события формируют поколения в детском возрасте. Дети, становясь взрослыми, родителями, руководителями, лидерами в зрелом возрасте, вершат историю. 
Авторы концепции утверждают, что этот цикл обычно совпадает с войной или вооруженным конфликтом. У. Штраус и Н. Хоу полагают, что после Второй мировой войны страны мира претерпевают схожие циклы общественного развития, которые порождают поколения с общими характеристиками.

Эпохи кризисов и пробуждений, связанные с возрастными периодами детства и молодости, производят архетипы четырех поколений: идеалистический - «пророк», реактивный - «кочевник», гражданский - «герой», адаптивный - «художник», которые последовательно в каждом цикле сменяют друг друга. Каждое поколение в соответствии с архетипом разделяет возрастное положение в истории, общественные установки и ценности по отношению, например, к семье, родине, риску, культуре, что сказывается на гражданской активности. Сформированные в раннем возрасте поколения развивают схожие коллективные личности и следуют аналогичным жизненным траекториям. У. Штраус и Н. Хоу считают, что длительность поколений обусловлена сложившимися социальными и биологическими этапами течения жизни и составляет около 20 лет. Однако границы поколений и поворотов истории неустойчивы, что диктуется событиями и ускорением технологических изменений, задавая секулярный ритм смены сезонов и архетипов [Howe, Strauss 1997].

Разрывы поколений. Российские исследователи в большей части заимствовали и развивали идеи основоположников теории поколений, отмечая различия, связанные с ценностями, стратегиями, идентичностью и поведением. Так, по мнению социолога Ю.А. Левады, проблема поколений в разных проявлениях возникает в условиях разрывов поколений и кризисов взаимоотношений. В традиционном обществе постепенная и размеренная смена поколений происходит прежде всего в кругу семьи. В посттрадиционных обществах возникают «ключевые поколения», которые диктуют «моду», выраженную в ориентациях и символах. «Разрывы» в установках и ценностях между возрастными группами вызывают воспроизводимый конфликт «отцов» и «детей». В свою очередь, конфликты поколений могут привести как к политическим изменениям, так и к социальным потрясениям. При этом социологический анализ исторического процесса связан не столько с демографическим поколением одного возраста, сколько со значимыми «поколенческими» группами, которые формируют особые механизмы и стандарты межличностного взаимодействия. Переломные моменты истории накладывают свой отпечаток на формирование ценностей возрастных групп и социализацию поколений.

На основании возрастной социализации Ю.А. Левада выделял два подхода к размежеванию поколений. Первый - элитарный - подход строится на вехах деятельности руководства государства, формирующего значимые события и исторические периоды. Второй - массовый - подход исходит из смены поколенческих типов и образов жизни в «низовых» группах населения. В рамках первого подхода в истории России XX в. он выделил шесть периодов и, следовательно, «значимых» поколений: 1) революционные изменения в период 1905-1930 гг.; 2) становление сталинской мобилизационной системы 1930-1941 гг.; 3) война и послевоенный в период 1941-1953 гг.; 4) период политической «оттепели» в 1953-1964 гг.; 5) период «застоя» 1964-1985 гг.; 6) период перестройки и демократических реформ 1985-1999 гг. При втором подходе смена поколений в массовых и локальных группах городских и сельских жителей обусловлена другими факторами и имеет иную хронологию, задаваемую такими событиями, как революция, войны, кризис, голод, индустриализация, коллективизация, миграция и т.д. Короткие периоды относительной социальной стабильности, наблюдаемые в царские, советские и постсоветские времена, не обеспечивали синхронность смены и преемствен- 
ности поколений. Левада предполагал, что люди 1975-1980 гг. рождения, вступившие в самостоятельную жизнь в 1990-е гг., станут наиболее активной группой, первым прагматичным поколением, которое лишено институционализированной исторической социальной памяти. По его мнению, новое поколение будет «свободно от памяти “советского наследия», от ожиданий свершений и разочарования надежд, от борьбы за социальные цели, получив в готовом виде политические и экономические “стены” своего дома, и озабочены лишь тем, как удобнее в нем устроиться» [Левада 2001]. Очевидно, что автор исходил скорее из своих идейных предубеждений, чем из реальных общественных изменений.

Стратегии поколений. Российский экономист П.А. Ореховский, рассматривая отечественную динамику поколений, обосновывает теоретическую модель карты стратегий. Смена поколений представляется своеобразной разверткой во времени процесса смены элит и руководствуется одной из следующих четыpex стратегий. Стратегия модерна предполагает открытое и публичное обсуждение ключевых вопросов жизни общества; стратегия непобежденного реализуется скрыто и предполагает выделение в социуме героев и толпы, неординарных личностей и обывателей, не способных выскочить из жизненной колеи и продолжающих жить «по накатанной»; стратегия ухода реализуется максимально открыто, проявляясь в нигилизме, отрицании существующих ценностей и авторитетов, создавших лживую и аморальную современность, в прорыве к истинным ценностям через самоуничтожение; стратегия малых дел предполагает улучшение мира без радикальных изменений существующего порядка избранными, которые руководят неразумным населением. Все четыре типа стратегий распределены в той или иной пропорции в возрастных когортах. Молодые люди, выбирая свою жизненную стратегию, становятся частью одного поколения. Однако по мере взросления человек не всегда продолжает следовать избранной стратегии и сохранять прежние нравственные установки и эстетические предпочтения. Межпоколенческие конфликты возникают из-за формирования в процессе социализации разных систем ценностей. Люди одного поколения, переживая общие значимые события, становятся своими, но в случае социального конфликта формируются чуждые друг другу поколения [Ореховский 2009].

Согласно концепции социальной идентичности, люди воспринимают себя и других на основе сходств и различий. Они определяют принадлежность к тому или иному поколению, выделяя в своей общности единые черты и в иных общностях - несходные характеристики. По мере того как люди создают группы внутри и вне поколенческих идентичностей, при взаимодействии между ними могут возникать конфликты. Обособление между поколениями происходит из-за человеческой потребности принадлежать к социальной группе, чтобы обеспечить чувство социальной причастности, гордости и самоуважения, но может также сформировать стереотипные представления о поколениях [Подвойский, Солеймани 2019].

Российский социолог В.Л. Пашинский раскрывает механизмы модели формирования поколений в процессе социализации. Процесс предполагает взаимодействие доминирующих и формирующихся поколений, представители которых проявляют отличающиеся типы поведения, рациональные по целям и ценностям. Исследователь исходит из логики, что «если внутри среды старших преобладает целерациональное поведение, а внутри молодежной среды - ценностнорациональное, то в своих прямых личных отношениях друг с другом они будут придерживаться двух принципиально разных рациональных ориентаций поведения и тем самым будут создавать условия для конфликта поколе- 
ний» [Пашинский 2013]. При этом конфликтная ситуация способствует взаимному отталкиванию и, как следствие, самоопределению социальных групп. Если следовать в русле западной теории социальных поколений, то конфликт возрастных групп также рассматривается как движущая сила общественного развития.

Цифровизация поколений. На современном этапе некоторые российские исследователи отмечают, что потенциал поколенческих моделей XX в. недостаточен для адекватного понимания процессов, происходящих в XXI в. Теоретическая модель передачи опыта от поколения к поколению М. Мид показала свои пределы для изучения трансформаций современных культурных форм передачи опыта в цифровой среде. Исследователи задаются целью создать в широком междисциплинарном контексте новые модели цифровой социализации и развития цифровой личности. Теоретические основания модели находятся в глобальных общественных трансформациях и технологических изменениях, а также современных социологических, психологических, культурных и философских концепциях развития [Солдатова 2018]. Пересмотр существующих концепций привел к развитию культурноисторической парадигмы, в рамках которой внимание уделяется экологической модели У. Бронфенбреннера [Bronfenbrenner 1979]. По мнению Г.У. Солдатовой, эта модель позволяет проводить систематический анализ личностного и когнитивного развития современного ребенка в контексте межпоколенческих отношений, а также опознавать как риски и угрозы цифровой среды, так и возможности и перспективы для позитивного развития молодого поколения. Обновленная методология обещает изучать социальнопсихологические характеристики цифрового поколения, цифровой разрыв и межпоколенческие взаимодействия.

В контексте «цифровой трансформации» особую важность представляет фактор технологических достижений в коммуникациях, которые кардинально изменили как систему культурных практик, так и способы передачи поколениям культурного опыта. Цифровая революция в коммуникациях приводит к формированию принципиально иной конфигурации отношений между поколениями, вызвав проблему распространения позитивного социального опыта в условиях неконтролируемого перепроизводства информации [Шурбе 2013].

Цифровизация массовых коммуникаций лежит в основе современных межпоколенческих разрывов в условиях усложнения социальных механизмов передачи культурного опыта. Однако исследователи отмечают, что одновременно с поколенческой конфликтностью развиваются практики межпоколенческого сотрудничества в цифровой среде и социально-сетевой социализации. При этом наставниками часто выступают младшие в отношении старших, особенно пожилых, помогая им адаптироваться к цифровой среде. Исходя из теории диффузии инноваций, цифровой разрыв поколений постепенно сглаживается [Глухов, Стаховская 2021].

Таким образом, каждая из представленных моделей формирования межпоколенческих отношений содержит свой набор факторов и механизмов. Ключевые модели межпоколенческих отношений открывают возможности для формирования программ прикладных исследований в соответствии с поставленными задачами. Выбор модели поколений в значительной степени диктуется предметом и контекстом исследования. 


\section{Список литературы}

Бродовская Е.В., Домбровская А.Ю., Пырма Р.В., Азаров А.А. 2019. Специфика критического мышления российской молодежи в условиях цифровизации. - Гуманитарные науки. Вестник Финансового университета. № 9(1). C. $14-23$.

Глухов А.П., Стаховская Ю.М. 2021. Цифровой разрыв в фокусе межпоколенческой коммуникации. - Вестник Томского государственного университета. Философия. Социология. Политология. № 59. С. 148-155.

Левада Ю. 2001. Поколения XX века: возможности исследования. Мониторинг общественного мнения: экономические и социальные перемены. № 5(55). С. 7-14.

Мангейм К. 2000. Очерки социологии знания: проблема поколений - состязательность - экономические амбииии (пер. с англ. Е.Я. Додина; отв. ред. Л.В. Скворцов). М.: Изд-во ИНИОН РАН. 162 с.

Мид М. 1988. Культура и мир детства: избранные произведения. М.: Наука. $430 \mathrm{c}$.

Ореховский П.А. 2009. Поколенческая динамика и новейшая история СССР - России (1950-2004 гг.). - Мир России. Социология. Этнология. Т. 18. № 4. C. 37-65.

Пашинский В.М. 2013. Социология знания о механизме формирования поколений. - Социологический журнал. № 1. С. 47-63.

Подвойский Д.Г., Солеймани С. 2019. Понятие социальной идентичности: основные исследовательские подходы. - Вестник Российского университета дружббы народов. Сер. Социология. Т. 19. № 4. С. 825-834.

Пырма Р.В. 2017. Восстание поколения z: новые политические радикалы. Гуманитарные науки. Вестник Финансового университета. № 7(2). С. 43-50.

Солдатова Г.У. 2018. Цифровая социализация в культурно-исторической парадигме: изменяющийся ребенок в изменяющемся мире. - Социальная $n c u$ хология и общество. Т. 9. № 3. С. 71-80.

Шатилов А.Б. 2019. «Мягкие» технологии российской власти по профилактике и нейтрализации экстремистских проявлений в молодежной среде в 2000-2010-е годы. - Гуманитарные науки. Вестник Финансового университета. № 9(1). С. 32-37.

Шурбе В.3. 2013. Поколение хайтек и «новый» конфликт поколений? Социс. Социологические исследования. № 4. С. 100-106.

Bengtson V.L. 1989. The Problem of Generations: Age Group Contrasts, Continuities, and Social Change. - The Course of Later Life: Research and Reflections (ed. by V.L. Bengtson, K.W. Schaie). N.Y.: Springer.

Bronfenbrenner U. 1979. The Ecology of Human Development: Experiments by Nature and Design. Cambridge, MA: Harvard University Press.

Foster K. 2013. Generation and Discourse in Working Life Stories. - The British Journal of Sociology. Vol. 64. Is. 2. P. 195-215.

Howe N., Strauss W. 1991. Generations: The History of America's Future, 1584 to

2069. N.Y.: William Morrow \& Company. 538 p.

Howe N., Strauss W. 1997. The Fourth Turning: What the Cycles of History Tell Us About America's Next Rendezvous with Destiny. N.Y.: Broadway Books.

Joshi A., Dencker J., Franz G. 2011. Generations in Organizations. - Research in Organizational Behavior. Vol. 31. P. 177-205. 
PARMA Roman Vasil'evich, Cand.Sci. (Pol.Sci.), Associate Professor of the Department of Political Science, Faculty of Social Sciences and Mass Communications, Financial University under the Government of the Russian Federation (49 Leningradsky Ave, GSP-3, Moscow, Russia, 1259930; rvparma@mail.ru)

\title{
THEORETICAL MODELS OF RELATIONS BETWEEN GENERATIONS OF CITIZENS
}

\begin{abstract}
In the context of social transformations, intergenerational relations are of interest to researchers as one of the important factors of change. The theoretical foundations of modern research are laid by several key generational models, including shifts, transmissions, cycles, breaks, strategies, and digitalization. Each of the designated models of generations considers various factors and mechanisms of the formation of relations, setting a special perspective for research.

Keywords: theory of generations, models of relations between generations, generational change, age differentiation, transmission of generations, generation cycles, generational gaps, generational strategies, digitalization of generations
\end{abstract}

РАСТОРГУЕВ Сергей Викторович - доктор политических наук, профессор департамента политологии факультета социальных наук и массовых коммуникаций Финансового университета при Правительстве РФ (125993, Россия, г. Москва, ГСП-3, Ленинградский пр-кт, 49; SRastorguev@ fa.ru)

\section{СТРАТЕГИЯ ПРЕОДОЛЕНИЯ МЕЖПОКОЛЕНЧЕСКИХ РАЗРЫВОВ В СОВРЕМЕННОЙ РОССИИ}

\begin{abstract}
Аннотация. В статье представлена стратегия преодоления межпоколенческих разрывов в современной России. Стратегия нацелена на сокращение ценностного разрыва трех возрастных групп, конгруэнтное перераспределение ресурсов между старшим, средним и младшим поколениями, минимизацию угрозы дискриминации по возрасту (эйджизма). Стратегия государства анализируется посредством модели пяти сил конкуренции М. Портера. Предложены конкретные проекты по развитию межпоколенческого диалога в экономической, политической, социальной, культурной сфере общества. Автор делает вывод, что в условиях цифровизации и глобализации молодежная политика должна быть адаптирована к новым вызовам.
\end{abstract}

Ключевые слова: поколения, межпоколенческий разрыв, молодежная политика, молодежь

$\mathrm{C}$ оциологические исследования, как правило, разграничивают поколения с интервалом в 15 лет, что представляется рациональным при анализе социальной динамики. При данном подходе чаще всего выделяются пять возрастных групп, что в большей степени позволяет охватить среднюю продолжительность жизни в развитых странах [Grasso 2014; Твенге 2019; Радаев 2020]. Иногда исследователи выделяют 7-8 возрастных групп, отводя каждой примерно по 10 лет [Keating et al. 2015]. Однако в целях изучения проблемы межпоколенческих коммуникаций и преодоления разрывов как внутри семьи (микроуровень), так и в обществе в целом (макроуровень) можно условно выделить три поколения, которые объединены общностью возрастного диапазона и сопричастностью к определенным политическим, экономическим и социальным 